WISSENSCHAFTSZENTRUM BERLIN FÜR SOZIALFORSCHUNG

SOCIAL SCIENCE RESEARCH CENTER BERLIN

Sebastian G. Kessing

Kai A. Konrad

\title{
Union Strategy and Optimal Income Taxation
}

SP II $2005-04$

January 2005

ISSN Nr. $0722-6748$

Research Area

Markets and Political Economy

Research Unit

Market Processes and Governance
Forschungsschwerpunkt

Markt und politische Ökonomie

Abteilung

Marktprozesse und Steuerung 
Zitierweise/Citation:

Sebastian G. Kessing, Kai A. Konrad, Union Strategy and Optimal Income Taxation, Discussion Paper

SP II 2005 - 04, Wissenschaftszentrum Berlin, 2005.

Wissenschaftszentrum Berlin für Sozialforschung $\mathrm{gGmbH}$, Reichpietschufer 50, 10785 Berlin, Germany, Tel. (030) 25491 - 0 Internet: www.wz-berlin.de 


\section{ABSTRACT}

\section{Union Strategy and Optimal Income Taxation}

by Sebastian Kessing and Kai A. Konrad

Restrictions on work hours are more important in countries with a large welfare state. We show that this empirical observation is consistent with the strategic effects of such restrictions in a welfare state in the context of optimal direct taxation in the tradition of Mirrlees (1971). Our results also apply to nonwelfarist states which have income redistribution, but not in purely extortionary states.

Keywords: Optimal income taxation, labor unions, work hours

JEL Classification: H21, H23

\section{ZUSAMMENFASSUNG}

\section{Gewerkschaftsstrategie und optimale Einkommensteuer}

Arbeitszeitbeschränkungen sind ein typisches Merkmal europäischer Wohlfahrtsstaaten. Wir zeigen, dass diese empirische Beobachtung mit den strategischen Wirkungen derartiger Restriktionen im Rahmen der Optimalsteuertheorie in der Tradition von Mirrlees (1971) übereinstimmt. Unsere Ergebnisse sind robust, solange die Regierung zumindest teilweise ein Umverteilungsziel verfolgt. 


\section{Introduction}

Restrictions on working effort or limits on working hours are well known union demands and are part of labor market regulations in many European welfare states. They are less common in more libertarian market economies where the welfare state is not so important. Evans et al. (2001) document that workers work fewer hours per year in typical welfare states such as the Scandinavian countries, Germany and the Netherlands than in the UK, the US or Australia and that these differences can be directly linked to the importance of restrictions on working hours in collective bargaining agreements and state regulations. Anxo and O'Reilly (2000) present a comparative description of different institutional arrangements that restrict working time, that shows their prevalence in European welfare states. In figure 1 we give data of high income OECD countries for yearly hours worked and the amount of government activity in the economy, where the latter variable is taken as a proxy for the extent of a welfare state. A strong negative relationship emerges, a finding that is robust to changing the years or using averages.

The theory of limits on working hours mostly concentrates on libertarian market economies and has not addressed the question why such restrictions are particularly strong and frequent in welfare states. Among these theories is the standard argument that such limits increase the relative scarcity of the type of labor they represent as a union. Further, in Lazear (1981), restrictions on hours worked arise as a necessary part of labor contracts in a world in which marginal product and wages differ optimally in response to moral hazard problems in a long term relationship between a worker and a firm. Similarly, specific capital models in the tradition of Mincer (1974) and Becker (1971) can imply constraints on hours, see Kahn and Lang (1991) for an empirical assessment of the explanatory power of agency and specific capital approaches. To our knowledge, none of these theories explain why 


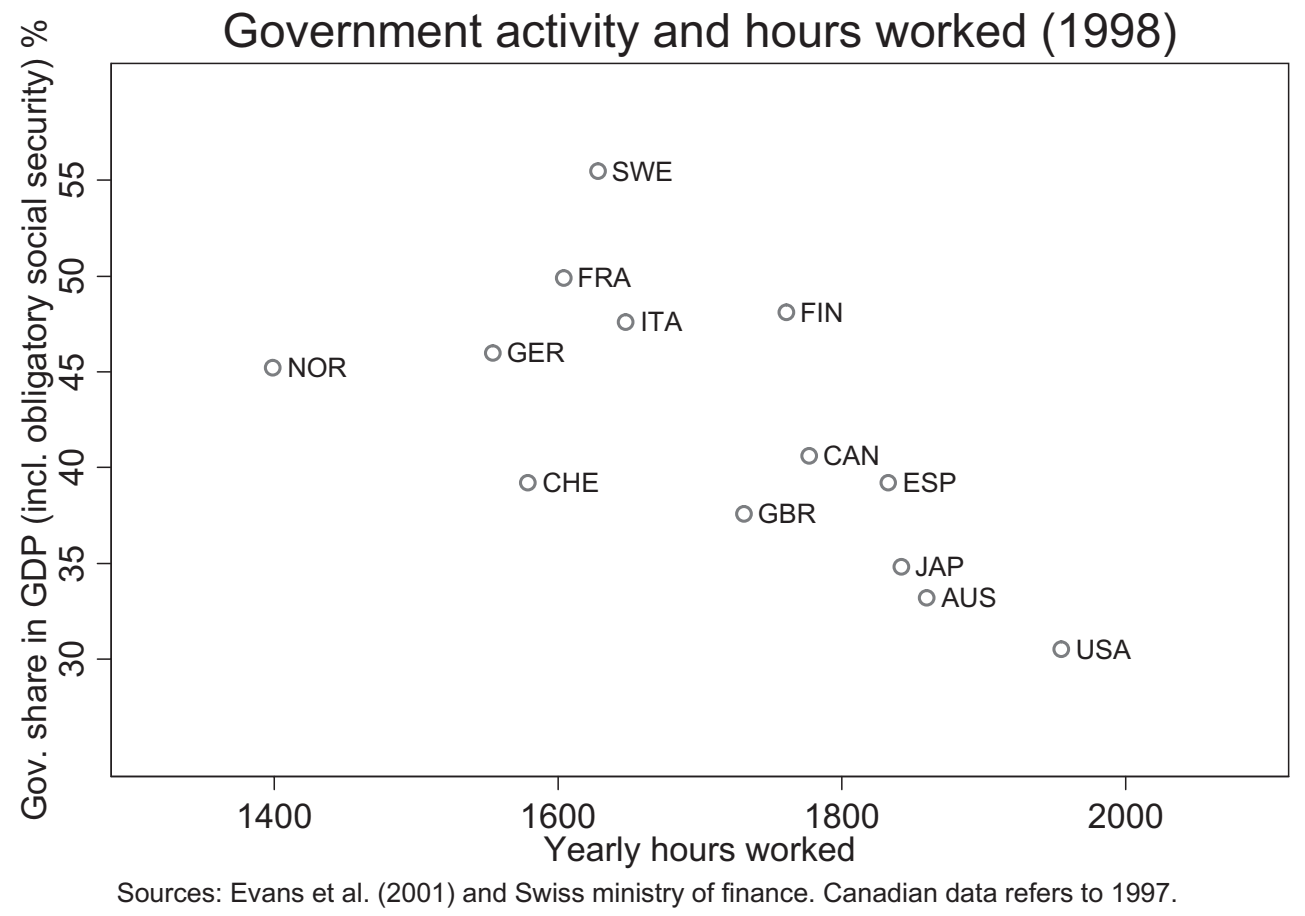

such restrictions are particularly pronounced in welfare states, and none of them address the interaction between these restrictions and redistributive taxation in a welfare state.

This paper provides a possible explanation for the empirical correlation. Welfare states redistribute from high-income earners to low-income earners and weigh this redistribution with its efficiency cost. Labor unions will anticipate the government's redistribution choice, and how it will respond to changes in the constraints. If the union negotiates working hour restrictions these will affect the redistribution choice. In this paper we show that the labor unions' policy of reducing working hours for the low income groups is highly rational from the perspective of the group of workers they represent if the redistributive tax system maximizes a social welfare function that gives 
positive weight to workers in all income groups. We will also argue that the same rationale applies more generally if the government policy enacts a redistribution programme regardless of whether this is driven by welfarist redistributional preferences, or more generally by a political process. However, governmental redistribution is crucial for the result. For instance, a purely extortionary government does not induce similar action by union representatives.

The optimal redistributive income taxation that is pursued by a welfarist government under some informational constraint as analysed in the classic papers on optimal taxation (Mirrlees 1971, Stiglitz 1982, Atkinson 1973) can be seen as a policy that maximizes the expected utility of each of a set of ex ante identical individuals who face some uncertainty about their future productivity type. ${ }^{1}$ We consider a government that follows this particular objective function. However, the specific weights of the utilities of the different groups in the government's objective function are not crucial for the result, and neither are the motivation, or the forces, that lead to this objective function of the government. We take the redistributional governmental objective as given and consider how union policy affects the actual redistribution outcome. $^{2}$ From this we draw conclusions about the unions' incentives with

\footnotetext{
${ }^{1}$ The optimal tax schedule is the unanimous choice of all individuals who choose a tax system under the veil of ignorance as this schedule is the optimal insurance contract that would also emerge if individuals could contract in insurance markets in a state prior to knowing their own productivity. See, e.g., Atkinson (1973) for discussion. The uncertainty about future income and productivity creates an insurance demand and this is the standard justification for redistributive optimal income taxation. Varian (1980) and Sinn (1995) have made this argument very clear. Agell and Lommerud (1992) take a similar point of view when considering wage compression as an insurance mechanism.

${ }^{2}$ In the theory of optimal direct taxation workers actually differ with respect to their types. This results in a major difference between this approach and economies with dual labor markets. For redistribution in these contexts, see, e.g., Lommerud, Sandvik and Straume (2003).
} 
respect to implementing maximum restrictions on effort or working hours. ${ }^{3}$

Our analysis parallels the approaches by Andersson (1996), Boadway, Marceau and Marchand (1996), Dillén and Lundholm (1996), and Konrad (2001) who highlight several other strategic aspects related to governmental redistributional policy. Our paper is also related to a new line of research in optimal direct taxation that gives it an important role and empirical relevance. Bourguignon and Spadaro (2002) consider the different income tax regimes in several countries and, instead of identifying the optimal tax schedule for given welfare functions, they identify the welfare functions that would make the respective observed country specific tax system an optimal tax schedule for this welfare function. This research suggests that the political process determines the weights of different interest groups in a country's welfare function, but the tax policy outcome is an efficient implementation of the resulting optimal redistribution programme. If this is the case, we can interpret our result differently as giving the labor unions the first move that can create an additional constraint for this policy formation of the tax programme. The tax programme had then to be implemented in this constrained environment. ${ }^{4}$

Our results provide an explanation for why restrictions on working hours

\footnotetext{
${ }^{3}$ Note that such maximum restrictions can be in line with the important general assumption in optimal income taxation that individuals' actual effort, and hence, their type, is private information and cannot be observed by others. We will discuss this when considering the formal analysis.

${ }^{4}$ There is also a recent literature which adds considerable insights to the classical optimal tax literature on the normative question of how to design the optimal tax schedule. Mild assumptions about preferences are sufficient to establish important qualitative properties of the optimal tax schedule (see, e.g., Diamond (1998), Saez (2001, 2002), and Homburg (2002a, 2002b). Our contribution differs from this line of research. We do not consider such optimal tax questions. Instead, we consider strategic questions. In particular, we ask how the unions can change the government's incentives to redistribute income within an optimal tax framework.
} 
and working conditions are particularly important in welfare states that is based on a strategic interaction between unions and a welfarist government. Intuitively, the group of low-income earners restrict their earnings capability, and, in the context of redistribution by a welfarist government, this will induce more redistribution towards this group. The actual results here are derived in Mirrlees' second-best framework of optimal income taxation. The strategic incentives that show up in this analysis are related to what has been discussed as the Samaritan's dilemma (Buchanan 1975, Bruce and Waldman 1990) or the "strategic advantage of being poor" (Konrad 1994) in different contexts. Unlike this literature, however, the mechanics are more indirect here, as they work via the effect of union policy on the individual incentive compatibility constraints.

We outline a framework that can analyse this interaction and establish the main results in section 2 . We show that unions have an incentive to reduce the constraint on effort for low-income earners below the level that results from the standard optimal tax programme. We also show that measures that uniformly reduce the productivity of the type of workers who already have low productivity can, but need not have similar strategic effects. In section 3 we discuss how, and to what extent, our results apply if governments are not welfarist. We argue that the qualitative findings are robust to worlds in which the political process reflects some preferences for redistribution between income groups, even if these preferences simply result from voting, lobbying or coalition formation of interest groups. We also show that the result does not sustain with purely extortionary governments. In section 4 we discuss some of the main assumptions made in the paper. Section 5 concludes. 


\section{Welfarist governments}

Consider the following version of a static two type optimal direct taxation model, similar to Stiglitz (1982). Let there be a continuum [0,1] of workers who are employed in an industry in which their gross income or wage equals their output that is perfectly observable and equal to $m_{i}$ for individual $i$. Generating these earnings brings a disutility of effort that depends on the amount of output and on the productivity of the individual. 'Nature' decides about each individual's productivity and there are two productivity types. Individuals who have low productivity need $e_{i}=m_{i}$ units of effort to generate $m_{i}$, whereas individuals who have high productivity have lower effort $e_{i}=$ $\rho m_{i}$, with $0<\rho<1$. A share $h$ of individuals is highly productive, the other share has low productivity. Individuals know their own productivity when making choices in the labor market, and the size of $h$ is common knowledge.

The workers' disutility of effort is measured by a function $\varphi\left(e_{i}\right)$ with derivatives $\varphi^{\prime}\left(e_{i}\right)>0, \varphi^{\prime \prime}\left(e_{i}\right)>0$, and $\varphi^{\prime \prime \prime}\left(e_{i}\right) \geq 0$. The marginal disutility of effort is positive, increasing in effort, and convex ${ }^{5}$. Since we will consider a direct mechanism in which the government offers contracts specifying gross and net incomes, we define the disutility in terms of gross incomes

$$
\psi_{H}(m) \equiv \varphi(\rho m) \text { and } \psi_{L}(m) \equiv \varphi(m)
$$

Once the workers know their own productivities, the union installs a mechanism that effectively constrains $e_{i}$ from above. Unions choose some $\bar{e}$ such that $e_{i} \leq \bar{e}$. We do not ask how exactly this constraint works and assume that this maximum constraint can be enforced without requiring actual effort to be observable. For instance, a time constraint from above will work. If there is a maximum of 35 working hours in a week that can be spent at the

\footnotetext{
${ }^{5}$ Convexity of the marginal effort function is assumed in order to rule out the desirability of a randomizing mechanism which has been discussed, e.g., in Stiglitz (1982).
} 
work place or the office, there is a limit on what a worker can do, but during these hours a worker can still exert more or less effort and do more or less work.

It is very important to note that the kind of unobservability of effort (and type) that is the starting point of optimal income taxation is fully compatible with the assumption of a labor union constraining total effort from above in the sense of such a maximum constraint, e.g., on working hours. This can be seen as follows. For the two types of productivities, the maximum constraint generates different sets of feasible output. The maximum output is $\bar{m}_{L}=\bar{e}$ for the less productive type and $\bar{m}_{H}=\bar{e} / \rho$ for the more productive type, with $\bar{m}_{L}<\bar{m}_{H}$ by $\rho<1$. The feasible output choices of the productivity types $L$ and $H$ are $[0, \bar{e}]$ and $[0, \bar{e} / \rho]$, respectively. If a worker generates output in the range $m \in[0, \bar{e}]$, the underlying effort and, hence, the worker's type, cannot be directly infered because both types could produce this output within the restrictions imposed. Only if a worker generates income above $\bar{e}$ can an inference be made about his type.

Once the constraint is chosen and implemented, the government solves an optimal taxation problem in the next stage that is the standard textbook two-types problem as in Stiglitz (1982), except for the additional constraint on maximum effort. For this purpose the government maximizes a welfare function subject to some constraints, both of which will be considered below. In the case with two types, optimal taxation will effectively consist of a menu of two pairs of gross income and net income, $\left(m_{H}, x_{H}\right)$ and $\left(m_{L}, x_{L}\right)$. Each individual will make a choice. The difference between gross and net income is a $\operatorname{tax} T_{H} \equiv m_{H}-x_{H}$ on the highly productive types and a subsidy $T_{L} \equiv m_{L}-x_{L}$ for the low productivity types. The sum of taxes just covers the sum of subsidies, and this defines the government's budget constraint.

Individuals $i$ care about their own consumption that equals their net income $x_{i}$ and about their effort $e_{i}$. We adopt the convention usual in optimal 
taxation that all individuals have the same utility function $u\left(x_{i}\right), i=H, L$. Individual consumption equals net income, $x_{H}=m_{H}-T_{H}$ for $H$ types and $x_{L}=m_{L}-T_{L}$ for $L$ types. The disutility from working was defined in (1) above by the functions $\psi_{i}(m), i=H, L$, using the relationship between output and effort.

With the share of highly productive workers given by $h$, the benevolent government's utilitarian welfare function is

$$
W=h\left[u\left(m_{H}-T_{H}\right)-\psi_{H}\left(m_{H}\right)\right]+(1-h)\left[u\left(m_{L}-T_{L}\right)-\psi_{L}\left(m_{L}\right)\right] .
$$

The government maximizes this objective function subject to the following constraints:

$$
\begin{gathered}
u\left(m_{H}-T_{H}\right)-\psi_{H}\left(m_{H}\right) \geq u\left(m_{L}-T_{L}\right)-\psi_{H}\left(m_{L}\right) \\
u\left(m_{L}-T_{L}\right)-\psi_{L}\left(m_{L}\right) \geq u\left(m_{H}-T_{H}\right)-\psi_{L}\left(m_{H}\right) \\
h T_{H}+(1-h) T_{L}=0 \\
m_{L} \leq \bar{e}
\end{gathered}
$$

and

$$
m_{H} \leq \bar{e} / \rho \text {. }
$$

Constraint $(2 \mathrm{~A})$ requires that an individual with high productivity prefers to generate (high) income $m_{H}$ and pay (high) taxes $T_{H}$ rather than (low) income $m_{L}$ and a tax/subsidy equal to $T_{L}$, that is, an individual with high productivity prefers $\left(m_{H}, T_{H}\right)$ to $\left(m_{L}, T_{L}\right)$, and chooses $\left(m_{H}, T_{H}\right)$ when making a choice between the two. Inequality $(2 \mathrm{~B})$ is an analogous constraint for individuals with low productivity. Constraint $(2 \mathrm{C})$ is the government's budget constraint. Constraints (2D) and (2E) are the additional maximum effort constraints that are chosen by the union in the state prior to the choice of tax policy. The government must choose a tax policy that is in line with these regulations. 
The union by assumption represents the low productivity group. Accordingly, its objective function is identical with the objective function of a worker with low productivity

$$
W_{L}=u\left(m_{L}-T_{L}\right)-\psi_{L}\left(m_{L}\right)
$$

Summarizing, the time structure of the game will be as follows. In STAGE 1, individuals $i \in[0,1]$ learn about their individual productivity. In STAGE 2 , the union implements a maximum effort. In STAGE 3 the government implements the Mirrlees (1971) optimal tax policy for a given distribution of productivities under the maximum effort constraint. This tax policy is an income tax (or subsidy) as a function of observed gross income, and possibly, as a function of productivity, if the government can observe individual productivity. In STAGE 4 each individual chooses his or her actual gross income and pays taxes or receives subsidies accordingly.

We state our main result in the following proposition:

Proposition 1 The union has an incentive to induce lower effort for low productivity workers than in the standard optimal income tax problem. The resulting equilibrium (i) benefits low productivity workers, (ii) harms high productivity workers and (iii) reduces welfare.

For a proof, we have to solve the game. First, as a benchmark, we consider the standard problem, without the additional constraints (2D) and (2E), as in Stern (1982) and Stiglitz (1982). The welfarist government chooses a pair of admissible combinations of gross earnings and taxes, $\left(m_{L}, T_{L}\right)$ and $\left(m_{H}, T_{H}\right)$, that maximize (2) subject to the constraints $(2 \mathrm{~A}),(2 \mathrm{~B})$, and $(2 \mathrm{C})$. As is well known, (2A) will be binding, whereas (2B) is not. The Lagrangian representing the maximization problem using $(2 \mathrm{C})$ to substitute for $T_{L}$ is

$$
\mathcal{L}=W+\lambda\left[u\left(m_{H}-T_{H}\right)-\psi_{H}\left(m_{H}\right)-u\left(m_{L}+\frac{h T_{H}}{1-h}\right)+\psi_{H}\left(m_{L}\right)\right] .
$$


The first-order conditions with respect to $m_{H}, m_{L}$ and $T_{H}$ are

$$
\begin{gathered}
(h+\lambda)\left[u^{\prime}\left(x_{H}\right)-\psi_{H}^{\prime}\left(m_{H}\right)\right]=0 \\
(1-h)\left[u^{\prime}\left(x_{L}\right)-\psi_{L}^{\prime}\left(m_{L}\right)\right]-\lambda\left[u^{\prime}\left(x_{L}\right)-\psi_{H}^{\prime}\left(m_{L}\right)\right]=0, \text { and } \\
-h u^{\prime}\left(x_{H}\right)+h u^{\prime}\left(x_{L}\right)+\lambda\left[-u^{\prime}\left(x_{H}\right)-\frac{h}{1-h} u^{\prime}\left(x_{L}\right)\right]=0 .
\end{gathered}
$$

These conditions have standard interpretations. For instance, (5) describes the "no distortion at the top" property of the solution, and the other conditions describe the equity-efficiency trade-off. By eliminating the Lagrange multiplier, (6) and (7) can be rearranged describing this tradeoff as

$$
u^{\prime}\left(x_{L}\right)-\psi_{L}^{\prime}\left(m_{L}\right)-\frac{u^{\prime}\left(x_{L}\right)-\psi_{H}^{\prime}\left(m_{L}\right)}{\frac{1-h}{h} u^{\prime}\left(x_{H}\right)+u^{\prime}\left(x_{L}\right)}\left[u^{\prime}\left(x_{L}\right)-u^{\prime}\left(x_{H}\right)\right]=0 .
$$

We denote the solution to this problem as $\left(\hat{m}_{H}, \hat{T}_{H}\right),\left(\hat{m}_{L}, \hat{T}_{L}\right)$ and by $\hat{x}_{H}$, $\hat{x}_{L}$ the corresponding consumption levels.

The union changes this optimization problem if it chooses $\bar{e}<\hat{m}_{L}$. In this case, (2D) becomes binding. Assuming that (2E) does not become binding in what follows, the first-order conditions become (5), (7), and $m_{L}=\bar{e}$ replaces (6). These conditions determine the optimal redistributive tax programme for a binding maximum effort for the low-income types.

A sufficient condition for the union to have an incentive to choose such a binding maximum effort is whether the utility of the low income employees increases at $\bar{e}=\hat{m}_{L}$ for a marginal reduction in $\bar{e}$. We consider this in two steps. First we calculate the reaction of the optimal tax transfer, if there exists an exogenous restriction on maximum effort and this restriction is changed. Second, we consider how this will affect the utility of the union members.

If $m_{L}$ is given exogenously and assumed to be binding, (6) drops from the solution of the redistribution problem. The remaining endogenous variables $m_{H}, T_{H}$ and $\lambda$ are implicitly defined by the system of (5), (7) and (2A). 
Using the implicit function theorem we can calculate the comparative static effect of a change in the exogenous $\bar{e}$ on the endogenous transfer $T_{H}$ from this entire system:

$$
\left.\frac{\partial T_{H}}{\partial \bar{e}}\right|_{\bar{e}=\hat{m}_{L}}=-\frac{\left[u^{\prime}\left(\hat{x}_{L}\right)-\psi_{H}^{\prime}\left(\hat{m}_{L}\right)\right]}{\frac{h}{1-h} u^{\prime}\left(\hat{x}_{L}\right)+u^{\prime}\left(\hat{x}_{H}\right)}<0 .
$$

A reduction in the hours constraint will cause an increase in the transfer. Although derived from the entire system, the intuition of this comparative static reaction originates in the nature of the incentive compatibility constraint. If $m_{L}$ is higher by one marginal unit, the utility of an $H$ type from pretending to be an $L$ type increases by $u^{\prime}\left(\hat{x}_{L}\right)-\psi_{H}^{\prime}\left(\hat{m}_{L}\right)>0$, i.e., by the difference in marginal consumption utility and marginal disutility from working if he worked and consumed like an $L$ type. This magnitude is given in the numerator. In order to keep the incentive compatibility constraint binding, the government needs to reduce the transfer from $H$ types to $L$ types accordingly. This transfer must be weighted with the marginal utilities and the potential difference in the number of high and low productivity types. This is given in the denominator. The working time reduction by the union weakens the incentive compatibility constraint the government is facing. This enables and induces the government to further increase the transfer from $H$ types to $L$ types.

We still have to see how the union's welfare will be affected. Using (9), the effect on its objective function of an increase in the hours constraint at $\hat{m}_{L}$ is

$$
\left.\frac{\partial W_{L}}{\partial \bar{e}}\right|_{\bar{e}=\hat{m}_{L}}=u^{\prime}\left(\hat{x}_{L}\right)-\psi_{L}^{\prime}\left(\hat{m}_{L}\right)-\frac{u^{\prime}\left(\hat{x}_{L}\right)-\psi_{H}^{\prime}\left(\hat{m}_{L}\right)}{u^{\prime}\left(\hat{x}_{L}\right)+\frac{1-h}{h} u^{\prime}\left(\hat{x}_{H}\right)} u^{\prime}\left(\hat{x}_{L}\right)<0
$$

This follows directly from comparing $\left.\frac{\partial W_{L}}{\partial \bar{e}}\right|_{\bar{e}=\hat{m}_{L}}$ with the government's redistribution efficiency tradeoff (8). This proves (i). Furthermore, the reduction in $m_{L}$ below $\hat{m}_{L}$ leads to an increase in $T_{H}$. Since (5) will still hold, this 
implies that $u\left(x_{H}\right)$ is reduced and $\psi\left(m_{H}\right)$ is increased, causing an overall reduction of the highly productive workers' utility. This confirms (ii). $W$ in (2) is reduced, since the resulting allocation is a feasible choice of the government in the standard problem without the additional constraint as well, and it was not optimal in this problem. This confirms (iii).

The intuition for the result is as follows. In the standard solution the utilitarian government reduces $m_{L}$ until the welfare loss from the distortion of the $L$ types is just offset by the welfare gain from an increase in the transfer from $H$ types to $L$ types that becomes feasible through this reduction. The transfer is weighted by the difference in marginal utilities. The union instead weighs the increased scope for an additional transfer dollar with the marginal utility of the $L$ types only.

As briefly discussed in the introduction, the effect is related to what has been discussed as the Samaritan's dilemma (Buchanan 1975, Bruce and Waldman 1990) or the "strategic advantage of being poor" (Konrad 1994) in different contexts. The $L$ types induce more redistribution from the $H$ types to their group by restricting their own work effort, and hence, their own gross income. Unlike in this literature, however, the mechanics are more indirect here, as they work via the effect of these restrictions on the incentive compatibility constraint.

Our main emphasis is on maximum working hours, as our analysis was stimulated by the strong empirical correlation between yearly working hours and the size of the welfare state. It may be interesting to note, however, that other measures that could be implemented by the unions have similar effects. This is illustrated by

Proposition 2 Suppose the union cannot implement a maximum $\bar{e}$, but can implement measures that reduce the L types' productivity. This can (but need not) benefit the group of $L$ type workers, harm $H$ types and reduce welfare. 
A proof is by way of an example in which a sufficiently large productivity reduction leads to the same outcome as the optimal choice of some $\bar{e}$. Recall the optimal choice of $\bar{e}$. We normalized the productivities of types such that $e_{i}=m_{L}$ for an $L$ type and $e_{i}=\rho m_{H}$ for an $H$ type. Depending on these productivities, the effort functions, utility functions and the share $h$ of $H$ types, in some cases the equilibrium choice of $\bar{e}$ that maximizes (3) taking into account the strategic effect (9) as in (10) may well be $\bar{e}=0$. Consider such a case. Suppose now that a constraint on effort is not feasible. Instead, suppose that unions can reduce the productivity of $L$ types by an appropriate choice of workplace regulation such that an $L$-type's effort $e_{i}$ generates only $e_{i} / k$ units of output. If $k$ can be chosen appropriately, the optimal tax equilibrium will lead to a solution of the optimal taxation problem with $\hat{m}_{L}=0$. In this case the productivity reduction for $L$ types has the same implications as the constraint $\bar{e}=0$.

Note that the result in Proposition 2 is a possibility result, whereas the result in Proposition 1 is much stronger and suggests that a reduction in maximum effort is always in the $L$ types' interest if, without such a reduction, the optimal tax problem has $\hat{m}_{L}>0$. More generally, we expect that a constraint on maximum effort is the superior instrument. Unlike the reduction of productivity of $L$ types that reduces their productivity of all units of $L$-types' effort, the limit in $\bar{e}$ keeps the productivity of intra-marginal effort units unchanged.

\section{Non-welfarist governments}

Many economists dismiss the view that governments are welfarist. We do not take a strong point of view on this matter here, as this only partially affects the results in the paper. For the strategic role of working restrictions in the low income sector, the question whether the redistributional policy of 
the government is welfarist or guided by other factors is mostly irrelevant. The effort constraint will generally change the government's optimization problem for any given objective function and, hence, the constraint will have an impact for the actual redistributional policy that will be implemented.

For instance, if the process of voting, coalition formation and lobbying leads to a particular objective function that may but need not resemble the objective function of a welfarist government, the advocates of the low income groups may still consider it advantageous to influence this process and the type of redistribution that is implemented if they can introduce restrictions that influence effort choices in an early stage of this process. An analysis of this problem will be less straight forward, as the political process needs to be specified, and it will generally interact with the union policy. As long as the political process leads to an incentive to redistribute from high income earners to low income earners, our basic argument applies: the low income group can typically increase the amount it receives from the high income group by restricting its own working effort.

The basic argument breaks down if the political process is mapped by a government's objective function that does not display redistributional preferences. For instance, in the extreme case in which governments behave as revenue maximizers and try to extract as much as possible from their constituency as outlined, e.g., in McGuire and Olson (1996) and Olson (1993), the objective function of the government becomes

$$
\mathcal{T}=h T_{H}+(1-h) T_{L}
$$

Without union policy, the government maximizes this objective function subject to the constraints $(2 \mathrm{~A})$ and $(2 \mathrm{~B})$ and to some reservation utilities of the two types of workers that, for simplicity, are normalized to

$$
u(0)-\varphi(0)=0 .
$$


Anticipating that only the incentive constraint for $H$ types $(2 \mathrm{~A})$ and the participation constraint (11) for $L$ types is binding, the Lagrangean is

$\mathcal{L}=\mathcal{T}+\lambda\left(u\left(m_{H}-T_{H}\right)-\psi_{H}\left(m_{H}\right)-u\left(m_{L}-T_{L}\right)+\psi_{H}\left(m_{L}\right)\right)+\mu\left(u\left(m_{L}-T_{L}\right)-\psi_{L}\left(m_{L}\right)\right)$

The first-order conditions with respect to $m_{H}, m_{L}, T_{H}$ and $T_{L}$ are:

$$
\begin{gathered}
\lambda\left(u^{\prime}\left(x_{H}\right)-\psi_{H}^{\prime}\left(m_{H}\right)\right)=0 \\
-\lambda\left(u^{\prime}\left(x_{L}\right)-\psi_{H}^{\prime}\left(m_{L}\right)\right)+\mu\left(u^{\prime}\left(x_{L}\right)-\psi_{L}^{\prime}\left(m_{L}\right)\right)=0 \\
h+\lambda\left(-u^{\prime}\left(x_{H}\right)\right)=0 \\
(1-h)+\lambda u^{\prime}\left(x_{L}\right)+\mu\left(-u^{\prime}\left(x_{L}\right)\right)=0 .
\end{gathered}
$$

By (12), the highly productive type's effort choice will again not be distorted. Denote the solution to this system of equations as $\left(\check{m}_{H}, \check{T}_{H}\right),\left(\check{m}_{L}, \check{T}_{L}\right)$, and the equilibrium levels of consumption as $\check{x}_{H}$ and $\check{x}_{L}$. We again ask whether a union that represents the low income earners wants to implement a maximum effort constraint.

Proposition 3 If the government maximizes $\mathcal{T}$ as in (2), the low productivity type cannot gain or lose from choosing some $\bar{e}$. However, such a choice reduces the utility of the extortionary government, and also harms the highly productive type.

Proof. The first-order conditions can be solved for $\lambda=\frac{h}{u^{\prime}\left(\check{x}_{H}\right)}>0$ and $\mu=\frac{1-h}{u^{\prime}\left(\check{x}_{L}\right)}+\frac{h}{u^{\prime}\left(\check{x}_{H}\right)}>0$. Accordingly, the low productivity type's participation constraint (11) is binding in the optimal solution. If the unions determine an $m_{L}$ that is lower than $\check{m}_{L}$ the resulting utility for low income types will still be equal to their reservation utility. Further, the reduction in the utility of the extortionary government follows from a revealed preference argument. The extortionary government could have implemented this effort 
as the second best optimal extortionary tax policy but has chosen a different tax policy. Third, as $\lambda>0$, the incentive compatibility constraint (2A) is binding. Therefore the utility of the $H$ type equals $u\left(m_{L}-T_{L}\right)-\psi_{H}\left(m_{L}\right)$. Using (11) this equals $\int_{0}^{m_{L}}\left(\psi_{L}(m)-\psi_{H}(m)\right) d m$ which is a strictly increasing function in $m_{L}$.

With an extortionary government, the low productivity types receive their reservation utility. For this reason they cannot gain from a choice of $\bar{e}$. However, an additional binding constraint $\bar{e}$ will be an additional constraint for the government, making it more difficult to extract revenue from the population. The additional constraint will reduce the taxes paid by the low income group. This also generates some additional slack regarding the incentive compatibility constraint and allows for higher taxes imposed on the high income earners. Hence, the high income earners would not want such a constraint.

\section{Discussion}

In this section we critically discuss a few assumptions made in the paper, explain whether our results are robust with respect to some changes in these assumptions, and discuss a few extensions.

More than two types We assumed that there are only two types of individuals who differ in their productivities. This assumption made the formal analysis particularly simple and allowed us to build on the well known two types model of optimal redistributive income taxation which public finance economists are particularly familiar with. If there is a larger set, or a continuum, of productivity types, then several adjustments need to be made. First, the objective function of the "union" might be less clear as this will not be a homogenous group of workers of a given type. The union will be most likely 
to represent the group of workers at the lower end of the income distribution more strongly than the workers at the extreme upper end. Accordingly, in this case too, the objective function of unions will be biased compared to a more balanced welfare function representing the whole population. Hence, qualitatively the same strategic incentives will remain. Further, with more than two productivity types too, further constraints on the gross earnings of the lower productivity types will change the incentive constraint for higher productivity types. It will typically lead to more redistribution. We therefore expect that our results generalize qualitatively to the many types case.

Endogenous types An important aspect of income taxation is that the productivity type is not fully exogenous. For instance, human capital investment may increase the probability of becoming highly productive. If individuals first choose their human capital investment, then privately find out about their productivity type, and then a welfarist government implements optimal income taxation, time consistent optimal redistributive income taxation leads to a hold-up problem and to under investment. This has been shown by Boadway, Marceau and Marchand (1996). Suppose a stage is added between the stage at which human capital investment is chosen and the stage at which the welfarist government implements optimal taxation, and in this additional stage the unions can implement a restriction on maximum effort as discussed in this paper. Then, as has been shown, the amount of redistribution will go up. As this amount is already too high in this framework, this time consistent union policy will further aggravate the time consistency problem outlined by Boadway, Marceau and Marchand (1996). Subsidized or mandatory education becomes even more desirable than in the case of time consistent redistributive taxation without labor unions. 
Globalization As has been pointed out in the context of tax competition, globalization, and the increase in mobility that could be implied by it, may reduce the scope for income redistribution. This may affect union policy in our context in several ways. If, for instance, the productive workers become fully mobile, this will eliminate the scope for welfarist redistribution completely. However, redistribution was the reason that made maximum effort constraints desirable from the perspective of unions. This will not be analysed more rigorously here, but there is a strong intuition that a reduction in the amount of redistribution that is feasible may make it advantageous for the unions to give up a policy of constraints on total working hours and other means for implementing maximum effort constraints.

\section{Conclusions}

Restrictions on work hours and effort are more prominent and important in countries with a large welfare state, or, more specifically, in states with considerable redistribution. We show that this observation is consistent with the strategic effects of such restrictions in a state in which the government redistributes from the high income group to the low income group. Intuitively, the constraints reduce both the pre-tax income and the effort of members in the low income group, but induces additional transfers of income from the high income group to the low-income group. We studied this problem in the context of optimal direct taxation in the tradition of Mirrlees (1971). However, the effect is more general and our results hold qualitatively if determinants other than the considerations of a welfarist government govern the redistribution of income. What is needed for the result is that there is some redistribution between income groups. For instance, in a purely extortionary government, the strategic incentive disappears. 


\section{References}

Agell, J., and K.-E. Lommerud, 1992, Union egalitarianism as income insurance, Economica, 59, 295-310.

Anderssson, F., 1996, Income taxation and job-market signaling, Journal of Public Economics, 59, 277-298.

Anxo D., and J. O'Reilly, 2000. Working time regimes and transitions in comparative perspective, in: O'Reilly, Cebrian, I. and M. Lallement, Working-time Changes, Edward Elgar, Cheltenham, 61-90.

Atkinson, A.B., 1973. How progressive should income tax be? in: M. Parkin and A.R. Nobay, eds., Essays in Modern Economics, Longman, London, 90-109.

Becker, G.S., 1971. Human capital: A theoretical and empirical analysis with special reference to education, 2nd ed. New York, Columbia University Press.

Buchanan, J.M., 1975, The Samaritan's dilemma, in: Edmund S. Phleps, ed., Altruism, morality and economic theory, New York: Russel Sage Foundation, 71-85.

Boadway, R., Marceau, N., Marchand, M., 1996. Investment in education and the time inconsistency of redistributive tax policy. Economica 63 (May), 171-189.

Bourguignon, F., and A. Spadaro, 2002, Social preferences revealed through effective marginal tax rates, paper presented at the ESEM 2002, DELTA, mimeo.

Bruce, N., and M. Waldman, 1990, The rotten-kid theorem meets the samaritan's dilemma, Quarterly Journal of Economics, 105, 155-65.

Diamond, P.A., 1998, Optimal income taxation: An example with a Ushaped pattern of optimal marginal tax rates, American Economic Review, 88(1), 83-95. 
Dillén, M., Lundholm, M., 1996. Dynamic income taxation, redistribution, and the ratchet effect. Journal of Public Economics 59 (1), 69-93.

Evans, J.M., Lippoldt, D.C. and P. Marianna, 2001. Trends in working hours in OECD countries, OECD Labour Market and Social Policy Occasional Papers No.45.

Homburg, S., 2002a. The optimal income tax: Restatement and extensions, mimeo.

Homburg, S., 2002b. Optimal marginal tax rates for low incomes: positive, negative, or zero? mimeo.

Kahn, S. and K. Lang, 1991. Constraints on the choice of work hours: Agency versus specific-capital, Journal of Human Resources, 27, 661-678.

Konrad, K.A., 1994. The strategic advantage of being poor: private and public provision of public goods. Economica, 61, 79-92.

Konrad, K.A., 2001. Privacy and time-consistent optimal labor income taxation, Journal of Public Economics, 79(3), 305-320.

Lazear, E., 1981. Agency, earnings profiles, productivity and hours restrictions, American Economic Review, 87, 606-620.

Lommerud, Kjell Erik, Bjorn Sandvik, and Odd Rune Straume, 2003. Good jobs, bad jobs and redistribution, University of Bergen, mimeo.

McGuire, Martin C., and Mancur Olson, Jr., 1996. The economics of autocracy and majority rule, Journal of Economic Literature, 34, 72-96.

Mincer, J.A., 1974. Schooling, experience, and earnings, New York, Columbia University Press.

Mirrlees, J.A., 1971. An exploration in the theory of optimum income taxation. Review of Economic Studies 38, 175-208.

Olson, M., Jr., 1993. Dictatorship, democracy, and development, American Political Science Review, 87(3), 567-676.

Saez, E., 2001. Using elasticities to derive optimal income tax rates, Review of Economic Studies, 68(1), 205-229. 
Saez, E., 2002. Optimal income transfer programs: intensive versus extensive labor supply responses, Quarterly Journal of Economics, 117(3), 10391073.

Sinn, H.-W., 1995. A theory of the welfare state. Scandinavian Journal of Economics, 97 (4), 495-526.

Stern, N.H., 1982. Optimum income taxation with errors in administration. Journal of Public Economics 17 (2), 181-211.

Stiglitz, J.E., 1982. Self-selection and Pareto efficient taxation. Journal of Public Economics 17 (2), 213-240.

Varian, H.R., 1980. Redistributive taxation as social insurance. Journal of Public Economics 14 (1), 49-68. 